\title{
BROOKHISEN
}

NATIONAL LABORATORY

BNL-107335-2015-JA

\section{Economic Evaluation of Distribution System Smart Grid Investments}

\author{
Ahmet Onen ${ }^{\mathrm{a} *}$, Danling Cheng ${ }^{\mathrm{d}}$, Robert P. Broadwater ${ }^{\mathrm{b}}$, Charlie \\ Scirbona $^{c}$, George Cocks ${ }^{c}$, Stephanie Hamilton ${ }^{f}$, Xiaoyu Wang ${ }^{f}$, \\ Jeffrey Roark ${ }^{\mathbf{e}}$ \\ a Department of Electrical and Electronics Engineering, Abdullah Gul University, Kayseri, Turkey. \\ b Department of Electrical and Computer Engineering, Virginia Polytechnic Institute and \\ State University, Blacksburg, VA, USA. \\ c Orange and Rockland Utilities Inc., Spring Valley, NY, USA. \\ d Electrical Distribution Design, Inc., Blacksburg, VA, USA. \\ e Electric Power Research Institute(EPRI), Palo Alto, CA, USA. \\ f Brookhaven National Laboratory, Upton, NY, USA. \\ *Corresponding author. Tel.: +90-352-224-8800; e-mail: ahmet.onen@agu.edu.tr (A. Onen) \\ Postal address: Abdullah Gul University (Sumer Campus), Kayseri, Turkey.
}

Submitted to the Journal of Electric Power Components and Systems

December 2014

\author{
Sustainable Energy Technologies Department \\ Brookhaven National Laboratory
}

\section{U.S. Department of Energy DOE Office of Science}


Notice: This manuscript has been co-authored by employees of Brookhaven Science Associates, LLC under Contract No. DE-AC02-98CH10886 with the U.S. Department of Energy. The publisher by accepting the manuscript for publication acknowledges that the United States Government retains a non-exclusive, paid-up, irrevocable, world-wide license to publish or reproduce the published form of this manuscript, or allow others to do so, for United States Government purposes.

\section{DISCLAIMER}

This report was prepared as an account of work sponsored by an agency of the United States Government. Neither the United States Government nor any agency thereof, nor any of their employees, nor any of their contractors, subcontractors, or their employees, makes any warranty, express or implied, or assumes any legal liability or responsibility for the accuracy, completeness, or any third party's use or the results of such use of any information, apparatus, product, or process disclosed, or represents that its use would not infringe privately owned rights. Reference herein to any specific commercial product, process, or service by trade name, trademark, manufacturer, or otherwise, does not necessarily constitute or imply its endorsement, recommendation, or favoring by the United States Government or any agency thereof or its contractors or subcontractors. The views and opinions of authors expressed herein do not necessarily state or reflect those of the United States Government or any agency thereof. 


\title{
Economic Evaluation of Distribution System Smart Grid Investments
}

\author{
Ahmet Onen $^{\mathrm{a}^{*}}$, Danling Cheng ${ }^{\mathrm{d}}$, Robert P. Broadwater ${ }^{\mathrm{b}}$, Charlie Scirbona ${ }^{\mathrm{c}}$, George Cocks ${ }^{\mathrm{c}}$, Stephanie Hamilton ${ }^{\mathrm{f}}$, Xiaoyu Wang ${ }^{\mathrm{f}}$, \\ Jeffrey Roark ${ }^{\mathrm{e}}$ \\ ${ }^{a}$ Department of Electrical and Electronics Engineering, Abdullah Gul University, Kayseri, Turkey. \\ b Department of Electrical and Computer Engineering, Virginia Polytechnic Institute and State University, Blacksburg, VA, \\ USA. \\ ${ }^{\mathrm{c}}$ Orange and Rockland Utilities Inc., Spring Valley, NY, USA. \\ ${ }^{\mathrm{d}}$ Electrical Distribution Design, Inc., Blacksburg, VA, USA. \\ ${ }^{\mathrm{e}}$ Electric Power Research Institute(EPRI), Palo Alto, CA, USA. \\ ${ }^{\mathrm{f}}$ Brookhaven National Laboratory, Upton, NY, USA. \\ *Corresponding author. Tel.: +90-352-224-8800; e-mail: ahmet.onen@agu.edu.tr (A. Onen) \\ Postal address: Abdullah Gul University (Sumer Campus), Kayseri, Turkey.
}

\begin{abstract}
This paper investigates economic benefits of smart grid automation investments. A system consisting of 7 substations and 14 feeders is used in the evaluation. Here benefits that can be quantified in terms of dollar savings are considered, termed "hard dollar" benefits. Smart Grid investment evaluations to be considered include investments in improved efficiency, more cost effective use of existing system capacity with automated switches, and coordinated control of capacitor banks and voltage regulators. These Smart Grid evaluations are sequentially ordered, resulting in a series of incremental hard dollar benefits. Hard dollar benefits come from improved efficiency, delaying large capital equipment investments, shortened storm restoration times, and reduced customer energy use. Analyses used in the evaluation involve hourly power flow analysis over multiple years and Monte Carlo simulations of switching operations during storms using a reconfiguration for restoration algorithm. The economic analysis uses the time varying value of the Locational Marginal Price. Algorithms used include reconfiguration for restoration involving either manual or automated switches and coordinated control involving two modes of control. Field validations of phase balancing and capacitor design results are presented. The evaluation shows that investments in automation can improve performance while at the same time lowering costs.
\end{abstract}

\section{Keywords}

Smart Grid investments, Monte Carlo simulation, Coordinated Control, Phase Balancing, Capacitor Design.

\section{INTRODUCTION}

Smart grid automation investments that result in making better use of existing distribution system capacity to improve efficiency, maintain required reliability at lower cost than classical design approaches, and that reduce customer costs are investigated in this work. Here smart grid investments are evaluated in terms of hard dollars. Benefits are quantified by comparing capital and operating costs of alternative designs. This stands in contrast to soft dollar benefits which often attempt to estimate the value of improvements in reliability. Soft dollar benefits are often difficult to justify. Here, a reduction in loss when the same load is supplied is counted as an energy savings and is included in the hard dollar evaluation.

The work here focuses on economic benefits, where the economic evaluations are based upon very detailed engineering analysis performed on a very detailed system model. The model used has a one-to-one correspondence with the geographical information system model of the system. The analysis is performed using hourly, time-varying loads and also hourly variations in the value of electric energy. Engineering analysis performed includes phase balancing, capacitor design, reconfiguration for restoration, Monte Carlo analysis, and coordinated control [1, 2].

The authors of [3] described a phase balancing algorithm that reduces losses but do not present an economic evaluation. Similarly, the authors of [4] explained design considerations for capacitor design to reduce losses, but do not present an economic evaluation. In [5] the authors described a model based distribution control scheme which is configurable and hierarchical, again without an economic evaluation. While [6] described a way to evaluate the impact of partial automation on system reliability, it does not present an economic evaluation of shortened storm response. The authors of [7-8] discussed the calculation of distribution system reliability indices using storm simulations but do not assess the economic value of improved storm response.

Hard dollar benefits from investments considered here arise from investing in automated switches, coordinated control of voltage regulators and capacitor banks, and preparatory actions of phase balancing and capacitor design. The preparatory actions 
are performed in order to get the most benefit from the automated switches and coordinated control, and they also result in efficiency improvements.

The analyses involves hourly power flow calculations over periods ranging from ten to 18 years, where hourly, time-varying loads are modeled and annual load growth factors by customer type are applied. Each individual customer is modeled along with the customers historical load measurements. Loads are modeled as voltage dependent, where a $1 \%$ load-voltage dependency is assumed. With this voltage dependency model, when the voltage decreases (increases) by $1 \%$, then the current drawn by a load will decrease (increase) by 1\%. Monte Carlo simulations [9] of switching operations during various types of storms are performed. The Monte Carlo storm simulations presented use statistical data derived from historical storms, and, for a specific type of storm, simulate up to 6000 hours of storm conditions to derive the results presented [10]. Algorithms used include reconfiguration for restoration [11], involving either manual or automated switches, and coordinated control involving two modes of control.

Electric energy prices are estimated on an hourly basis for the analysis periods. Using historical Locational Marginal Price (LMP) data, the historical LMP data is escalated based upon the U. S. Department of Energy's forecast for gas energy prices. Thus, the assumption is made that electric energy prices escalate as gas energy prices do. Hence, the time varying cost of electricity is modeled along with the time varying load on an hourly basis. Validations using field measurements are presented for the phase balancing and capacitor designs considered.

Cost benefits derive from: 1-Increased system efficiency; 2-Rapid access to existing system capacity; 3-Shortening the length of storm responses; and 4- Reduction in load energy. A soft benefit is improved customer reliability. Cost benefits among the investments are presented and compared.

This paper is organized as follows: Evaluations to be performed are described in section 2. In sections 3-7 alternative ways of operating the system are compared, in each case using two different models. As the paper progresses from section 3 to 7 , the comparisons build on one another from section to section, so that the incremental worth of an investment made on top of another investment can be assessed. Conclusions are presented in section 8.

\section{DESCRIPTIONS OF SYSTEM USED AND DESIGN TO BE EVALUATED}

The Orange and Rockland Utilities system used in the evaluations is shown in Fig.1. The system consists of 14 feeders supplied by seven different substations. Of particular interest is a substation that has 7 feeders. This substation, which is shown as a star in Fig.1, will be used in a substation deferral study associated with maintaining reliability. Feeders from other substations that interface with feeders from the substation of interest are modeled to create the system studied here.

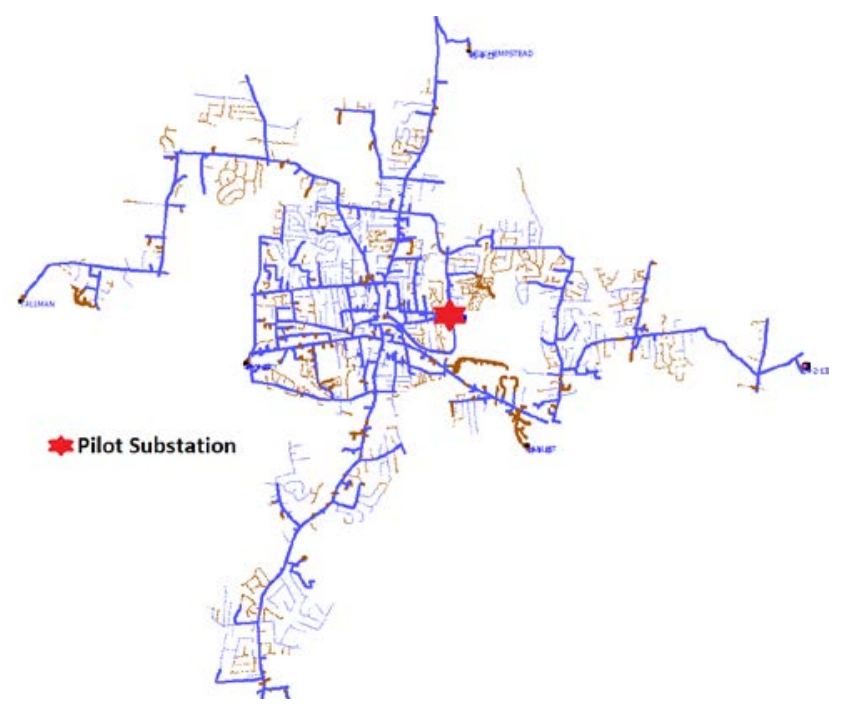

Fig.1. System studied in smart grid investment evaluations

Table I presents information related to substations, feeders, and components in the system, including controlled devices. The system has 16 fixed shunt capacitors, 12 switched shunt capacitors, and 1 voltage regulator. The capacitors listed in Table I are actually determined in the capacitor design study described below, but are listed here for completeness in describing the model. 
TABLE I

Component Types and count of components

\begin{tabular}{|l|c|}
\hline Component Type & $\begin{array}{c}\text { Numbers } \\
\text { for 14 Feeder } \\
\text { Model }\end{array}$ \\
\hline Primary Overhead Lines & 6027 \\
\hline Line Cutouts & 828 \\
\hline Overhead Distribution Transformers & 2148 \\
\hline Overhead Step Transformers & 14 \\
\hline Voltage Regulators & 1 \\
\hline Reclosers & 78 \\
\hline Switched Capacitors & 12 \\
\hline Fixed Capacitors & 16 \\
\hline Gang Operated Air Breaks & 45 \\
\hline Disconnect Switches & 286 \\
\hline Underground Primary Cables & 2917 \\
\hline Underground Distribution Transformers & 1292 \\
\hline Underground switches & 32 \\
\hline Busses (transmission/distribution) & 8 \\
\hline Transformers (transmission/distribution) & 15 \\
\hline Breakers (transmission/distribution) & 8 \\
\hline
\end{tabular}

Table II presents information about customers modeled in the system. The load on the system consists of residential, industrial and small commercial customers, totaling 21991 customers served by 2148 overhead distribution transformers. In the Monte Carlo reliability evaluations described below, when equipment failures cause customer interruptions, the customers without power are counted in the calculations to determine reliability. In the voltage violations described in the coordinated control evaluation, low voltages at the 2148 distribution transformers are considered.

TABLE II

Customer Types and Numbers of Customers by Type

\begin{tabular}{|c|c|}
\hline Class Name & $\begin{array}{c}\text { Customer } \\
\text { Numbers for 14 } \\
\text { Feeder Model }\end{array}$ \\
\hline Residential & 19227 \\
\hline Small Commercial Type & 2160 \\
\hline Large Commercial Type & 506 \\
\hline Traffic Light- 100W & 4 \\
\hline Single Large Load Type & 94 \\
\hline Total Number of Customer & 21991 \\
\hline
\end{tabular}

\subsection{Description of Design Cases and Method of Cost Comparison Evaluations}

Prior to any design changes, the model shown in Fig. 1 is referred to as the Base Case Model. Following phase balancing design, a Phase Balanced Model is created. Then, capacitor design is performed on the Phase Balanced Model, creating the Capacitor Design Model. Finally automated switches are placed in the Capacitor Design Model, and a coordinated control system is added to the Capacitor Design Model, creating the Automated Model. Thus, altogether there are four different models that are used in the economic evaluations.

Cost comparisons are made between the Base Case Model and the Phase Balanced Model, and again cost comparisons are made between the Capacitor Design Model and the Phase Balanced Model. Thus, the incremental worth of the investment in capacitors can be determined. Two types of automation are included in the Automated Model, automated switches and coordinated control. Two modes of coordinated control are used, Conservation Voltage Reduction (CVR) mode and a Voltage Violation mode override. Cost comparisons are made between the Capacitor Design Model and the Automated Model for the following: 1-Storm restorations; 2-Substation Deferral 3-Customer energy use and feeder losses.

The cost comparisons include worth of losses, energy costs, labor costs, and equipment costs, but do not include the cost of the backbone communication system and the cost of the control center. Thus, costs of phase balancing, switched capacitor banks, automated reclosers, automated switches, automation of capacitor banks and voltage regulators, equipment installation costs, and hourly costs of field crews during storms are considered in the comparisons. 
Based upon using individual customer load measurements and load research statistics, the loads vary from hour to hour in the analysis [12]. The feeders are analyzed on an hourly basis over a ten year period, and the losses for each hour are calculated. Electric energy prices are estimated on an hourly basis. Using historical LMP data, historical LMP data is escalated based upon the U. S. Department of Energy's forecast for gas energy prices [13]. Thus, the losses at a given hour are multiplied by the forecasted LMP price for that hour to determine the dollar worth of the losses. Fig. 2 shows a plot of the LMP versus month of year used in the analysis.

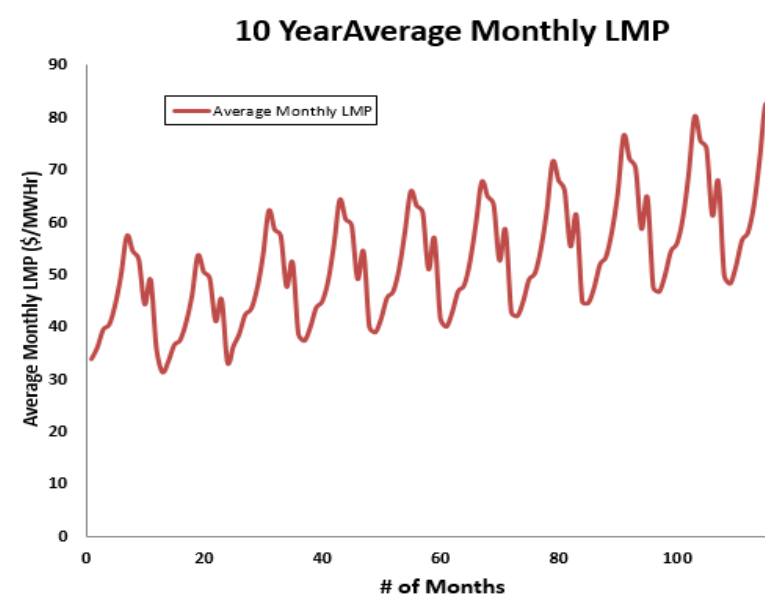

Fig.2. Average monthly LMP price used in analysis

Forecasted customer load growth is included in the analysis, and is especially important in the substation deferral evaluation between the Capacitor Design Model and the Automated Model.

\section{Phase Balanced Model Versus Base Case Model Evaluation}

The Base Case model represents the system as initially configured prior to any design changes. Phase balancing and capacitor placement for time varying loads are considered as preparatory actions for smart grid investments. The "first step" for preparing for the smart grid automation is phase balancing. The phase balancing algorithm used in the analysis prioritizes the phase moves, with the highest priority phase move providing the greatest reduction in losses over the time-varying load, the next highest priority phase move providing the next greatest reduction in losses, and so forth [15]. Even with feeders that have over 100 single-phase laterals, phase moves for three laterals are often sufficient to achieve 95\% or more of the loss reduction available.

Using start-of-circuit phase current measurements from a SCADA historian, the phase balancing design changes were validated. Fig. 3 shows phases A, B, and C current flows obtained from the SCADA historian. During the approximately five day period shown in Fig. 3 the feeder was phase balanced. The phase balancing operation occurred where the three current flows come close together.

Balancing over the time-varying load also balances, and for three-phase loads increases, the system capacity that is available to automated switches. Phase balancing should be performed before capacitor placement, since the phase balancing result affects phase loading and power factors that affect capacitor placement. Performing phase balancing prior to capacitor design can sometimes result in improved control with fewer capacitors and lower cost [14]. 


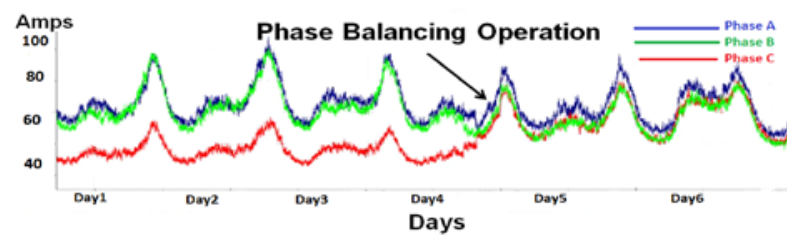

Fig.3. Validation of phase balance design with SCADA historian phase current measurements

The cost of phase balancing the 14 feeders was $\$ 163 \mathrm{k}$. Including the cost of the phase balancing, the Phase Balanced Model provided non-discounted efficiency savings of $\$ 94 \mathrm{k}$ over the Base Case Model for the 10 year period.

\section{CAPACITOR DESIGN MODEL VERSUS PHASE BALANCED MODEL EVALUATION}

Capacitors can be used to reduce system losses [16] and control voltages. Following phase balancing, the next step in preparing for the smart grid automation was to perform and implement the capacitor design and then to validate the results with field measurements. The feeders considered here originally had existing capacitor banks, and so the study here may also be thought of as a capacitor redesign study. As a result of the capacitor design using the time-varying load, many of the existing capacitor banks were moved and/or changed out with new banks of different sizes. Capacitor design over the time varying load improves the ability of the coordinated control to manage voltage. Table III shows also capacitor replacement operation results from field measurement to validate results of capacitor design over power factor.

TABLE III

Validation of Capacitor Design

\begin{tabular}{|l|l|l|l|}
\hline Substation & Transformer Bank & $\begin{array}{l}\text { Power Factor Before } \\
\text { Design }\end{array}$ & $\begin{array}{l}\text { Power Factor After } \\
\text { Design }\end{array}$ \\
\hline Substation A & 1 & 0.9620 & 0.9702 \\
\hline Substation A & 2 & 0.9347 & 0.9950 \\
\hline Substation B & 3 & 0.9759 & 0.9865 \\
\hline
\end{tabular}

The economics of the Capacitor Design model was compared against the economics of the Phase Balanced model. The cost of purchasing and installing new capacitors is used in the evaluation. In the economic comparison the worth of the difference in losses between the Phase Balanced Model and the Capacitor Design Model is compared over the 10 year period. The cost of equipment and installation labor for the 12 switched capacitors and 16 fixed capacitors was $\$ 564 \mathrm{k}$, where fixed capacitors cost \$16k and switched capacitors cost \$20k. The Capacitor Design Model provided non-discounted efficiency savings of \$227k over the Phase Balanced Model for the 10 year period.

\section{AUTOMATED MODEL VERSUS CAPACITOR DESIGN MODEL: SWITCH AUTOMATION AND STORM RESTORATION}

Recent storms impacted the utility with costs in the neighborhood of $\$ 25$ to $\$ 35$ million dollars $[9,17]$. During a storm event the hourly costs of crews is high [8, 9, and 18]. Switch automation allows crews to skip operating switches and go directly to repairs [19-20]. However, there are approximately 4 manual switches for every automated switch in the design considered here. A concern is whether or not the reliability of the system can be maintained with so few automated switches relative to the manual switches.

Table IV shows different storm type descriptions considered in the analysis, with the average length in hours of each storm type [9]. 
TABLE IV

Storm classification and parameters

\begin{tabular}{|c|c|c|c|}
\hline Storm Type & $\begin{array}{c}\text { T Range } \\
(\mathbf{~ o F ~})\end{array}$ & $\begin{array}{c}\text { Wind Speed } \\
\text { (mph) }\end{array}$ & $\begin{array}{c}\text { Average } \\
\text { Length } \\
\text { (hours) }\end{array}$ \\
\hline $\begin{array}{c}\text { High temperature, } \\
\text { no strong wind }\end{array}$ & MaxT $>80$ & WS $<=20$ & 56 \\
\hline $\begin{array}{c}\text { High temperature, } \\
\text { strong wind }\end{array}$ & MaxT $>80$ & WS $>20$ & 84 \\
\hline $\begin{array}{c}\text { Low temperature, } \\
\text { no strong wind }\end{array}$ & MinT $<32$ & WS $<=20$ & 55 \\
\hline $\begin{array}{c}\text { Low temperature, } \\
\text { strong wind }\end{array}$ & MinT $<32$ & WS $>20$ & 146 \\
\hline $\begin{array}{c}\text { Moderate temperature, } \\
\text { no strong wind }\end{array}$ & $\begin{array}{c}\text { MaxT }<=80 \\
\text { MinT }>=32\end{array}$ & WS $<=20$ & 35 \\
\hline $\begin{array}{c}\text { Moderate temperature } \\
\text { strong wind }\end{array}$ & $\begin{array}{c}\text { MaxT }<=80 \\
\text { MinT }>=32\end{array}$ & WS $>20$ & 53 \\
\hline \multicolumn{2}{|c|}{ MaxT: maximum temperature; MinT: minimum temperature; } \\
WS: wind speed
\end{tabular}

Fig. 4 shows a representative schematic of the automated switch design, where just two feeders are considered. Each feeder has a midpoint recloser and there is a tie recloser between the feeders. Customer counts between the automated SCADA switches are limited to approximately 250 customers. Altogether 63 automated SCADA switches were installed in the 14 feeder system.

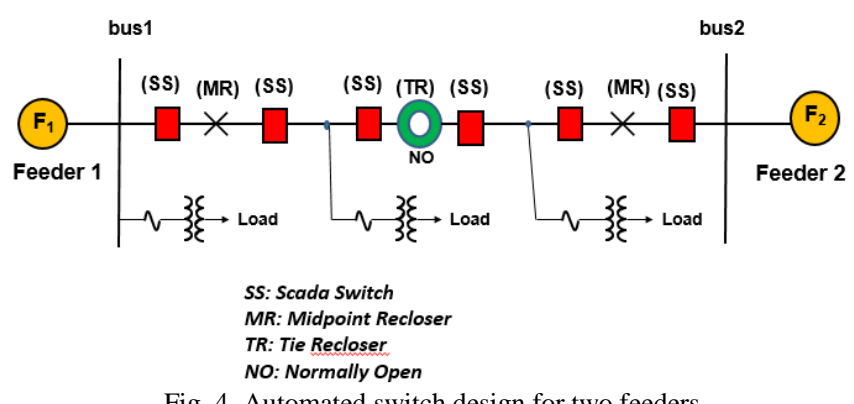

Monte Carlo simulations are performed for both the Capacitor Design Model, which just has manual switches, and the Automated Model, and then comparisons of the storm restoration between the two models are performed. The Monte Carlo simulation randomly selects and fails components based on the statistics of the storm type being simulated. In performing the storm restoration calculations, each time a component is failed, the Monte Carlo simulation employs a reconfiguration for restoration algorithm to operate switches, where in the Capacitor Design Model manual switches are operated, and in the Automated Model only automated switches are operated [21]. The simulation iterates through the hours of the storm, and then repeats a new storm simulation, until convergence of the Monte Carlo process occurs. In the simulation it is assumed that the operation of an automatic switch takes 0 hours. For a given failure, it is assumed that the operation of the first manual switch requires 1 hour, and the operation of each additional manual switch associated with the failure requires 15 minutes each. These operation times were derived from the utility operating experience.

It is assumed that it takes no crew time for automated switch operations. Table V shows results from the simulation for low temperature, strong wind storms. From Table V it may be seen that on average there are 460 automated switch operations with the Automated Model and 1069 manual switch operations with the Capacitor Design Model, requiring 403 hours of crew time. The interruption hours for the customers are divided into hours associated with the switching events and hours associated with the repair. Note that the Automated Model has fewer hours of interruption. 
TABLE V

Results of Monte Carlo Simulations Comparing Capacitor Design Model with Automated Model for Low

Temperature, Strong Wind Storm

\begin{tabular}{|c|c|c|c|c|c|r|}
\hline Model & $\begin{array}{c}\text { Automatic } \\
\text { Device } \\
\text { Operations }\end{array}$ & $\begin{array}{c}\text { Manual } \\
\text { Device } \\
\text { Operations }\end{array}$ & $\begin{array}{c}\text { Hours Spent } \\
\text { In Switching } \\
\text { Operations }\end{array}$ & $\begin{array}{c}\text { Interruption } \\
\text { Hours due to } \\
\text { Switching } \\
\text { Event }\end{array}$ & $\begin{array}{c}\text { Interruption } \\
\text { Hours due to } \\
\text { Repair Event }\end{array}$ & $\begin{array}{c}\text { Total Hours } \\
\text { of } \\
\text { Interruption }\end{array}$ \\
\hline $\begin{array}{c}\text { Capacitor } \\
\text { Design } \\
\text { Model }\end{array}$ & 0 & 1069 & 403 & 337736 & 2474736 & 2812471 \\
\hline Automated & 460 & 0 & 0 & 0 & 2623756 & 2623756 \\
\hline
\end{tabular}

Table VI, column 2, shows the average number of hours crews spend operating manual switches for each storm type as simulated with the Capacitor Design Model. Table VI also provides averages for the number of crews working each storm type, the cost per hour of the storm type, the number of storms of each type that occur in a 10 year period, and non-discounted savings of the Automated Model over the Capacitor Design Model during the 10 year period.

When performing cost benefit analysis, we assume automation of the 14 feeder system is representative of automation of entire system. From Table VI we can see that the overall storm response is shorter on average with the Automated Model due to the manual switching time of the Capacitor Design Model. For instance, in the low temperature, strong wind storm, crews are going to spend on average 2.4 hours operating manual switches, where this does not occur in the Automated Model. Thus, the low temperature, strong wind storm response is on average shortened by 2.4 hours. Low temperature, strong wind storms cost on average $\$ 120 \mathrm{k}$ per hour. Thus, shortening the storm response by 2.4 hours saves on average $\$ 283 \mathrm{k}$ per low temperature, strong wind storm. Over the ten year period, the Automated Model has a non-discounted savings of $\$ 7,646 \mathrm{k}$ in storm restoration over the Capacitor Design Model, where this savings represents savings extrapolated to the whole system based upon the results of the 14 feeder simulation.

TABLE VI

Monte Carlo simulation results for Capacitor Design Model and Savings of Automated Model versus Capacitor Design Model over a ten year period

\begin{tabular}{|l|c|c|c|c|c|}
\hline \multicolumn{1}{|c|}{ Storm Type } & $\begin{array}{c}\text { Capacitor } \\
\text { Design Model } \\
\text { Switching } \\
\text { Hours per } \\
\text { Storm }\end{array}$ & $\begin{array}{c}\text { Number of } \\
\text { Crews } \\
\text { Working } \\
\text { Storm }\end{array}$ & $\begin{array}{c}\text { Storm Cost } \\
\text { per Hour } \\
\mathbf{( \$ k )}\end{array}$ & $\begin{array}{c}\text { Number of } \\
\text { Storms in 10 } \\
\text { Year Period }\end{array}$ & $\begin{array}{c}\text { Savings in 10 } \\
\text { Years } \\
\mathbf{( \$ k )}\end{array}$ \\
\hline High Temperature & 40 & 100 & 70 & 13 & 364 \\
\hline Moderate Temp & 60 & 100 & 70 & 12 & 504 \\
\hline $\begin{array}{l}\text { High Temperature } \\
\text { Strong Wind }\end{array}$ & 213 & 142 & 100 & 17 & 2550 \\
\hline $\begin{array}{l}\text { Moderate Temp } \\
\text { Strong Wind }\end{array}$ & 168 & 142 & 100 & 23 & 2721 \\
\hline Low Temperature & 127 & 171 & 120 & 7 & 624 \\
\hline $\begin{array}{l}\text { Low Temperature } \\
\text { Strong Wind }\end{array}$ & 403 & 171 & 120 & 10 & 2830 \\
\hline
\end{tabular}

\section{AUTOMATED MODEL VERSUS CAPACITOR DESIGN MODEL: SWITCH AUTOMATION AND SUBSTATION DEFERRAL}

The substation that is the focal point in the 14 feeder system for this study is illustrated in Fig. 5 . It has seven feeders that interface to feeders from other substations in the system. The substation has two transformers. Reliability requirements specify that if either transformer fails, then $62 \%$ or more of the load must be picked up either using capacity from the remaining transformer in the substation or from neighboring substations through switching operations. 38\% or less of the load must be picked up within 24-hours by using a portable substation. However, the total customer hours of interruption must be maintained 
below 60,000 [22]. In the simulations the substation transformers are allowed to operate for 4 hours on Long Term Emergency Ratings. Note that the substation is designed with an auto-power tie breaker as shown in Fig. 5.

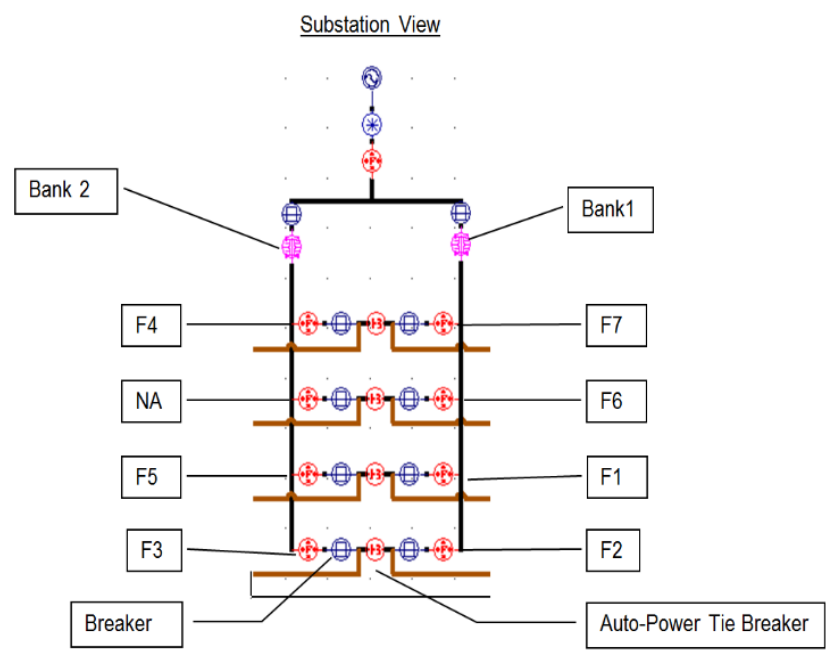

Fig.5. Substation considered in substation deferral study.

Using customer load growth projections for the feeders, as illustrated for a representative feeder in Fig.6, the load on the system is grown until the reliability requirement cannot be satisfied. This is done for both the Capacitor Design Model and the Automated Model. When the Capacitor Design Model can no longer meet the reliability requirement, the cost of building a new substation to meet the reliability requirement is evaluated. The cost of adding the automated switches to the Automated Model is also evaluated, and a comparison between the costs of the Capacitor Design Model and the Automated Model is performed.

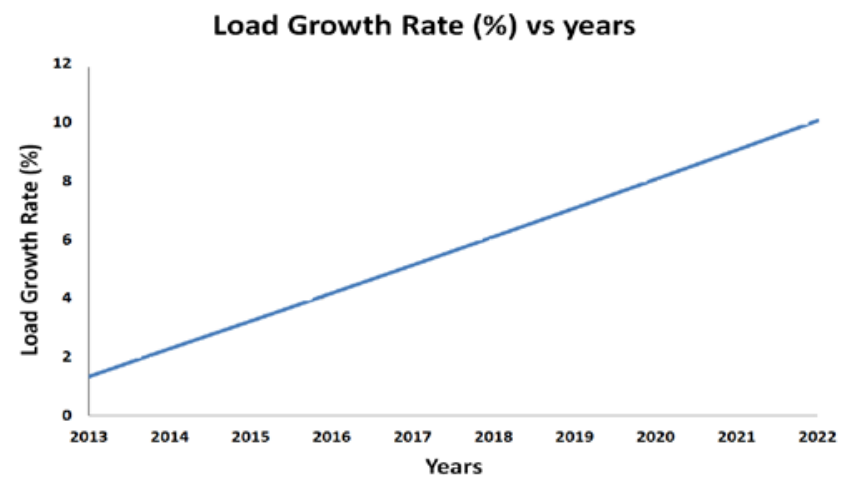

Fig.6. Sample feeder with percentage load growth rate used in study

Fig.7 shows the results from comparing the Capacitor Design Model with the Automated Model when transformer bank 2 of Fig.5 is failed. From Fig.7 it may be seen that the outage hours increase as a function of year, due to the annual load growth rates, for the bank failure. 


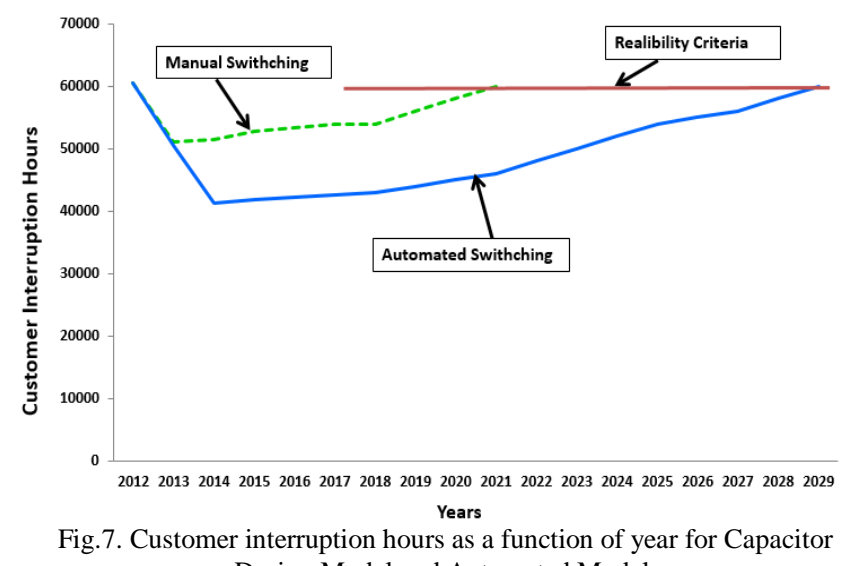

Design Model and Automated Model.

The Capacitor Design Model, which has only manual switches, violates the reliability requirement of 60000 customer outage hours in 2021, whereas with the Automated Model the reliability requirement is not violated until year 2029. The cost of the new substation that is eventually going to be required is estimated to be $\$ 40000 \mathrm{k}$ in 2012 dollars. Thus, with the automated design, this capital investment is delayed for 8 years. In this comparison the Automated Model has a present worth savings of \$7,014k over the Capacitor Design Model.

\section{AUTOMATED MODEL VERSUS CAPACITOR DESIGN MODEL: COORDINATED CONTROL}

The coordinated control runs in the control center and makes use of measurements from throughout the system to determine control settings that move the system toward optimum performance as the load varies. The coordinated control provides set points to local controllers. A major difference between the coordinated control and local control is the set points provided by the coordinated control are time varying. Here the coordinated control works with switched capacitors and voltage regulators.

The coordinated control considered has two modes: 1-Conservation Voltage Reduction (CVR) mode to reduce the energy drawn by loads; 2-Voltage override mode that overrides the CVR mode if voltage violations occur.

Table VII compares energy between the Automated Model coordinated control CVR mode and the Capacitor Design Model, where a $1 \%$ load-voltage dependency is used. The feeder loss reduction achieved with the coordinated control is small because the Capacitor Design Model is already operating at a very high efficiency. The average feeder efficiency in the Capacitor Design Model is 0.9855 , whereas the average feeder efficiency in the Automated Model is 0.9859 , an increase of only 0.0004 in efficiency. However, due to CVR mode, over the 10 year period the non-discounted savings in energy of the Automated Model over the Capacitor Design Model was \$2,064k. The cost of automating the 12 switched capacitors and one voltage regulator in the 14 feeder system is $\$ 68 \mathrm{k}$.

The voltage violations that occurred with the Automated Model were significantly less than those that occurred with the Capacitor Design Model. There were 2486 load points at which voltage violations were monitored over 8760 analysis points per year for 10 years, or 217,773,600 customer load voltage calculations. Over these load voltage calculations, $1.57 \%$ of the calculations in the Capacitor Design Model were low voltages and only $0.20 \%$ of the calculations in the Automated Model running the CVR mode were low voltage. In the Automated Model the control mode switches to voltage override when low voltages are encountered, so the Automated Model worked to eliminate low voltages [1].

TABLE VII

Comparison of Automated Model Coordinated Control CVR mode with Capacitor Design Model for 10 year period

\begin{tabular}{|c|c|c|}
\hline Model & $\begin{array}{c}\text { Total Energy Supplied } \\
\text { (MWHr) }\end{array}$ & $\begin{array}{c}\text { Reduction in Energy } \\
\text { (MWHr) }\end{array}$ \\
\hline Capacitor Design Model & 6853554.431 & 0 \\
\hline $\begin{array}{c}\text { Automated Model } \\
\text { coordinated control CVR } \\
\text { mode }\end{array}$ & 6802631.573 & 50922.858 \\
\hline
\end{tabular}

\section{Conclusions}

This paper investigates the economics of smart grid automation investments in an incremental fashion by comparing the 
performance of different designs. Five economic comparisons are performed involving the worth of phase balancing, capacitor design, automated switches for providing rapid access to backup capacity with major transformer failures, the value of automated switches for storm restoration, and the value of coordinated control CVR mode. Validations of the phase balancing and capacitor design efforts are presented, and to some extend these validations provide confidence in the model that is used for the reconfiguration and coordinated control functions.

The investments in phase balancing and capacitor design for the time varying load provide efficiency improvements along with providing balanced capacity for automated switching (and increased three-phase load capacity), and capacitor device placement that is more optimal for coordinated control. The largest economic benefit is derived from the investments in automated switches that better utilize the existing system capacity, delaying much larger investments in new substations. The automated switches provide both economic and reliability benefits in substation deferral and also during storm conditions. A substation deferral study shows that reliability requirements with the automated system were satisfied for eight years longer than with the manually operated system. That is, the manually operated system required significant capital investment in a new substation eight years sooner than the automated system. Furthermore, the automated switches provide significant cost benefits by helping to shorten the length of storm responses.

Finally, benefits of coordinated control are evaluated. If the controls were designed for the time varying load, then it is shown that the economic benefit from using coordinated control to minimize feeder losses can be small. However, if loads have sufficient voltage dependency, significant energy dollar savings can be realized by using coordinated control with CVR mode. Coordinated control, which evaluates voltages at all customer loads and creates time-varying setpoints that are provided to local controllers, results in significantly better voltage control than the use of local control that only uses a few voltage measurements and works with fixed setpoints.

The worth of the efficiency improvements and load energy reductions for the 14 feeder system over the 10 year period was $\$ 4,736$. The present value worth of the substation deferral was $\$ 7,014 \mathrm{k}$. The automated switches also reduced storm response times, and an estimate of the worth of this savings for the whole system came to $\$ 7,646$. As has been shown in many other industries, investments in automation can improve performance while significantly reducing costs.

\section{ACKNOWLEDGMENT}

The authors would like to thank Electrical Distribution Design, Inc, Orange \& Rockland Utilities and Brookhaven National Laboratory for providing data, funding, and technical assistance.

\section{REFERENCES}

[1] A.Onen, D.Cheng, R. Arghandeh, J. Jung, J. Woyak, M. Dilek, R. Broadwater, "Smart Model-based coordinated control based on feeder losses, energy consumption, and voltage violations," Electric power system component and system, vol. 41, issue 16, pages 1686-1696, August, 2013.

[2] J.Jung, A.Onen, R. Arghandeh, R. Broadwater, "Coordinated Control of Automated Devices and Photovoltaic Generators for Voltage Rise Mitigation in Power Distribution Circuits”, Renewable Energy 66C, pp 532-540, January 2014.

[3] M. Dilek, R. Broadwater, J. Thompson, R. Sequin, "Simultaneous Phase Balancing at Substations and Switches with TimeVarying Load Patterns,” IEEE Transactions on Power Systems, Nov. 2001, Vol. 16, No. 4, pp. 922-928.

[4] Osama M. Aloquili, Nazih M. Abu-Shikhah, "Power Factor correction capacitors for utilizing power consumption in industrial plants”, International Journal of Energy Technology and Policy 2010 - Vol. 7, No.3 pp. 288 - 308

[5] Josh Hambrick, Robert Broadwater, “Advantages of Integrated System Model-Based Control for Electrical Distribution System Automation”, Proceedings of 18th IFAC World Congress, Aug. 28 - Sept. 2, 2011, Milano, Italy.

[6] K.Alekhya, P.S.R. Murthy and C. Bhargava “ Assessment of Reliability for Distribution feeders on the bases of cost analysis” Bonfring international journal of power system and integrated circuits, vol. 1, special issues, December 2011.

[7] Nagaraj Balijepalli, Subrahmanyam S. Venkata, Charles W. Richter, Richard D. Christie, Vito J. Longo “ Distribution system reliability assesment due to lighting storm’ IEEE transaction on power delivery, Vol. 20, No.3, July 2005.

[8] R. E. Brown, S. Gupta, R.D Christie, S.S. Venkata, R. Fletcher "distribution system reliability assessment: momentary interruptions and storms” IEEE transaction on power delivery, Vol.12, No. 4, October 1997.

[9] Jaesung Jung, Yongju Cho, Danling Cheng, Ahmet Onen, Reza Arghandeh, Murat Dilek, Robert P Broadwater "Monte Carlo analysis of plug-in hybrid vehicles and distributed energy resource growth with residential energy storage in Michigan” Applied Energy 2013; Vol. 108, pages 218-235.

[10] Danling Cheng, Yishan Liang, Dan Zhu, Robert P. Broadwater, Real-Time Power Electric System Modeling, Assessment and Reliability Prediction, Power Systems Conference and Exposition, 2009. PSCE '09. IEEE/PES, 15-18 March 2009

[11] David Kleppinger, Robert Broadwater, Charlie Scibona, “Generic reconfiguration for restoration” in Elsevier Electric Power System Research, volume 80 issue 3, march 2010, pages 287-295.

[12] Robert Broadwater, Al Sargent, Abdul Yarali, H. Shaalan, Jo Nazarko "Estimating Substation Peaks From Load Research Data” IEEE Transactions on Power Delivery, Vol. 12, No. 1, pp. 451-456, January 1997.

[13] U.S. Energy Information Admisnistration, “Short-Term Energy Outlook report”, February 2013. 
[14] M. Dilek “Integrated Design of Electrical Distribution Systems: Phase Balancing and Phase Prediction Case Studies, Ph.D. Dissertation, Virginia Polytechnic Institue and State University, March 2001.

[15] M. Dilek, R. Broadwater, “An Introduction to Integrated Design in Electrical Distribution,” Proceedings of PES 2002 Winter Meeting, January 27-31, 2002, New York, NY.

[16] Tanuj Manglani, Y.S Shishodia, “A survey of optimal capacitor placement techniques on distribution lines to reduce losses”, International Journal of Recent Research and Review, Vol. I, March 2012.

[17] Bradley W. Johnson, “After the Disaster: Utility Restoration Cost Recovery”, Edison Electric Institute Report, February 2005.

[18] Thomas H. Fritts, "Economic cost of electrical system instability and power outages caused by snakes on the Island of Guam”, International Biodeterioration \& Biodegradation 49 (2002) 93 - 100.

[19] R. N. Allan and R. Billinton, Reliability Evaluation of Power Systems: Springer, 2001.

[20] Hesham E. Shaalan, "Using automated switching techniques to meet future power demands", The technology interface, Vol. 2, No. 3, spring 1998.

[21]D. Kleppinger "Prioritized Reconfiguration of Interdependent Critical Infrastructure Systems, Ph.D. Dissertation, Virginia Polytechnic Institue and State University, March 2009.

[22] U.S. Department of Energy Case Study "Model-Centric” Approach to Smarter Electric Distribution Systems”, January, 2012. 